\title{
A PRODUÇÃO DE RESUMOS ACADÊMICOS: UM ESTUDO PRELIMINAR SOBRE A USABILIDADE DO SOFTWARE “AUTORIA-MEU RESUMO”
}

\section{Marília de Carvalho Caetano-Oliveira*}

RESUMO: Este trabalho é parte de minha pesquisa de pós-doutoramento, realizada de março de 2019 a fevereiro de 2020, que teve por objetivo investigar aspectos relacionados ao ensino-aprendizagem de resumos acadêmicos. Neste artigo, daremos ênfase à discussão dos resultados dos testes de usabilidade do software "AutorIA", cuja criação foi um desdobramento da referida pesquisa. Esses testes tiveram como objetivo analisar o processo de interação entre os estudantes e o computador, verificando, assim, a facilidade de uso do sistema. (CONRAD; LEVI, 2002). O aporte teórico para a elaboração do software fundamentou-se numa perspectiva híbrida: por um lado, baseamo-nos nos princípios do Interacionismo Sociodiscursivo proposto por Bronckart (1999, 2006) e Cristóvão (2013), bem como sua vertente didática, nos termos de Schneuwly e Dolz (2004). Por outro lado, utilizamos aspectos da Sociorretórica de Swales (1990) e Askehave; Swales (2001), priorizando o modelo Create a Research Space (modelo CARS) e suas possíveis adaptações ao gênero resumo acadêmico. A metodologia, vinculada à Linguística Aplicada, teve uma perspectiva qualitativa de cunho interpretativista (MOREIRA; CALEFE, 2008), com a utilização de métodos empíricos. Os resultados revelaram que os estudantes, de modo geral, avaliaram positivamente a utilização do programa na produção de resumos acadêmicos, ratificando, assim, que a tecnologia pode ser um importante recurso no processo de didatização.

PALAVRAS-CHAVE: Resumo acadêmico; Software; Testes de Usabilidade.

\section{Introdução}

O presente trabalho é um recorte de minha pesquisa de pós-doutoramento, intitulada "O processo de produção de resumos acadêmicos: reflexões e desdobramentos", realizada sob a supervisão da $\operatorname{Prof}^{a} \operatorname{Dr}^{\mathrm{a}}$ Marta Cristina da Silva, pertencente à Universidade Federal de Juiz de Fora. A referida pesquisa teve por objetivo refletir sobre o processo de

\footnotetext{
* Doutora em Linguística e Língua Portuguesa (Puc-MG). Professora efetiva do Departamento de Letras, Artes e Cultura da Universidade Federal de São João del-Rei (UFSJ). Na área de pesquisa, desenvolve, atualmente, o projeto intitulado O processo de produção de gêneros acadêmicos: reflexões e desdobramentos. A partir de novembro de 2018, passou a integrar o grupo de pesquisa da UFSJ Letramentos, gêneros e ensino (LEGEN), coordenado pela Prof ${ }^{a}$ Laura Silveira Botelho.
} 
ensino-aprendizagem de resumos acadêmicos. Como desdobramento, foi criado o software "AutorIA", tendo por função colaborar no processo de didatização do referido gênero.

Neste artigo, especificamente, objetivamos analisar os resultados obtidos a partir dos testes de usabilidade realizados com estudantes do curso de Letras de uma universidade pública do interior de Minas Gerais no uso do software em questão.

Teoricamente, assumimos um viés híbrido, suportado pelas abordagens do Interacionismo Sociodiscursivo e da Sociorretórica.

Entender e operacionalizar tais modelos poderá facilitar a elaboração de estratégias de ensino-aprendizagem da produção de resumos na universidade, já que, muitas vezes, o desempenho dos estudantes nesse processo não tem se mostrado satisfatório.

\section{O Interacionismo Sociodiscursivo (ISD)}

A tese central do ISD "é que a ação constitui o resultado da apropriação, pelo organismo humano, das propriedades da atividade social mediada pela linguagem" (BRONCKART, 1999, p. 42). Dessa forma, o ISD "reforça a centralidade da ação de linguagem e particularmente da ação significante - nos processos de textualização pelos quais se materializam as condutas especificamente humanas nas práticas sociais de interação verbal" (MATÊNCIO, 2007, p. 57).

Nesse sentido, Bronckart (2005) propõe cinco princípios gerais do ISD: a) o desenvolvimento e o agir das condutas humanas seriam o único foco das ciências humanas; b) os processos de desenvolvimento são apoiados nos pré-construtos humanos; c) o agir resulta em conhecimentos construídos; d) o desenvolvimento da socialização e da individu-

\footnotetext{
${ }^{1}$ Para a produção dessa ferramenta, foi firmada uma parceria com os professores Fernando Augusto Teixeira e Alex Vidigal Bastos, pertencentes ao Departamento de Tecnologia em Engenharia Civil, Computação e Humanidades da Universidade Federal de São João del-Rei, Campus Alto Paraopeba (CAP). Compuseram também a equipe os estudantes Álvaro Henrique Santos Ribeiro (Engenharia de Telecomunicações) e Matheus Cezário dos Santos (Engenharia Mecatrônica), ambos alunos do CAP.
} 
alização são duas perspectivas que se complementam e são inseparáveis no desenvolvimento humano; e) o desenvolvimento é incontestavelmente afetado pela linguagem (BRONCKART, 2005, p. 234-5).

Dessa forma, os textos são "produtos da atividade humana e, como tais, [...] estão articulados às necessidades, aos interesses e às condições do funcionamento das formações sociais no seio das quais são produzidos" (BRONCKART, 1999, p. 72).

Esse conceito de Bronckart retoma a definição de gênero de Bakhtin (1992), complementando que, para realizarmos uma ação de linguagem, é necessário explorar as formas comunicativas que estão sendo usadas numa formação social, o que é uma visão de gênero como construto social.

Machado (2005), baseada em Bronckart (1999[1996]), afirma que o gênero pode ser modificado pelas produções que são realizadas e que há um processo de reprodução-adaptação de gêneros e esse processo é considerado "gerador de novos exemplares de textos, mais ou menos diferentes dos modelos preexistentes. E é pelo acúmulo desses processos individuais que os gêneros se modificam continuamente e assumem um estatuto fundamentalmente dinâmico e histórico" (MACHADO, 2005, p. 251).

Essa variabilidade, porém, não invalida a possibilidade de sistematização do ensino do gênero e, para que os objetivos sejam atingidos, as práticas escolares precisam ser orientadas por um modelo didático do gênero a ser ensinado. Segundo de Pietro et al. (1996/1997, p. 108 apud Machado e Cristóvão, 2006, p. 556-7), o modelo didático é “um objeto descritivo e operacional, construído para apreender o fenômeno complexo da aprendizagem de um gênero. [...] permitiria a visualização das dimensões constitutivas do gênero e seleção das que podem ser ensinadas e das que são necessárias para um determinado nível de ensino".

Os autores afirmam ainda que esse modelo não precisa ser nem perfeito nem puro teoricamente e que as capacidades para a apreensão de gêneros não são adquiridas naturalmente, necessitando de uma aprendizagem social, e essa aprendizagem deve estar articulada 
ao ensino dos discursos (de Pietro et al. (1996/1997, p. 108 apud Machado e Cristóvão, 2006, p. 168).

Dessa forma, o meio mais eficiente para o aluno compreender a forma como os sujeitos realizam ações nas práticas sociodiscursivas é criar estratégias de ensino-aprendizagem, considerando textos em situações reais de produção, recepção e circulação. Além disso, não se pode negligenciar a responsabilidade dirigida aos professores e aos que ensinam línguas, já que estes, a partir de seu trabalho, podem modificar as relações sociais de poder (MATÊNCIO, 2007, p. 61-2).

Machado e Cristóvão (2006) ressaltam que os gêneros só podem ser considerados como ferramenta para o agir dos sujeitos quando estes se apropriarem efetivamente daqueles, considerando-os úteis para o agir com a linguagem. Caso contrário, "se os aprendizes não sentirem necessidade de um determinado gênero para seu agir verbal, haverá muito maior dificuldade para sua apropriação" (MACHADO; CRISTÓVÃO, 2006, p. 551).

Com relação a essas ações de linguagem, Dolz; Pasquier; Bronckart (2017 [1993]) postulam que elas se constituiriam em três níveis:

capacidades de ação, isto é, aptidões para adaptar a produção de linguagem às características do contexto e do referente; capacidades discursivas, ou aptidões para mobilizar os modelos discursivos pertinentes a uma ação determinada; por fim, capacidades linguísticodiscursivas ou capacidades de domínio das múltiplas operações psicolinguísticas exigidas para a produção de um discurso singular. (DOLZ; PASQUIER; BRONCKART, 2017 [1993], p. 164)

Conforme verificado, as capacidades de linguagem abrangem desde aspectos contextuais até aqueles referentes à materialidade linguística. Além das capacidades supracitadas, Cristóvão e Stutz (2011), propõem outras capacidades, que as autoras denominaram de capacidades de significação. Estas surgiram devido à necessidade de demonstrar aspectos mais amplos da produção e entendimento de textos na aprendizagem de línguas. Em outros termos, essas capacidades dariam conta do plano do discurso/ideologia (CRISTÓVÃO, 2013, p. 372). 
Com o advento dos textos multimodais, surgiu ainda a necessidade de propor novas capacidades de linguagem: as multissemióticas (CMS). Estas referem-se a "semioses outras que não são transmitidas através da materialidade daquilo que é verbal” (LENHARO, 2016 apud MIQUELANTE, 2019, p. 91). A autora afirma ainda que, além da relevância para análise de textos multimodais, as CMS podem também colaborar na produção e compreensão de textos orais e escritos, principalmente, aqueles que são constituídos por linguagem verbal, não verbal e audiovisual.

O aporte teórico-metodológico construído por Bronckart (1999) propõe uma análise descendente, indicando que, primeiramente, sejam investigadas as condições de produção de um texto e depois a infraestrutura textual. Para que as condições de produção sejam analisadas, é necessário considerar os parâmetros do mundo físico e do mundo sociossubjetivo.

Os parâmetros do mundo físico referem-se ao emissor e ao receptor reais e espaço físico em que o texto é produzido; os parâmetros do mundo sociossubjetivo dizem respeito às posições sociais do emissor e do receptor, a formação social, a esfera social e o objetivo da interação. Além desses fatores, dentro do contexto de produção, também é analisado o conteúdo temático do texto, ou seja, o assunto tratado.

A arquitetura interna do texto é formada por três camadas que se relacionam: infraestrutura geral do texto, mecanismos de textualização e mecanismos enunciativos. A infraestrutura é composta pelo plano geral do texto (organização do conteúdo temático), pelo tipo de discurso (da ordem do Expor e do Narrar, bem como suas fusões), sequencialidade (narrativa, descritiva, argumentativa, explicativa, dialogal) e formas de planificação.

Por sua vez, os mecanismos de textualização contemplam “articulações hierárquicas, lógicas e temporais que contribuem para a estruturação do conteúdo temático” (STRIQUER, 2014, p. 320), sendo eles: a conexão, a coesão nominal e a coesão verbal. Já os mecanismos enunciativos contribuem para o estabelecimento da coerência pragmática do texto, fazendo-se presentes pelas vozes expressas no texto e pelos modalizadores. 
Dessa forma, podemos verificar a validade desse modelo proposto por Bronckart, já que oferece ferramentas para lidar com a complexidade dos gêneros, pois abrange fatores tanto contextuais quanto linguístico-discursivos.

\section{A Sociorretórica de Swales (1990)}

Swales (1990) propõe uma perspectiva que se baseia na análise de aspectos linguísticos que revelam muito da construção do texto e das práticas sociais (acadêmicas e profissionais) que determinam as escolhas linguísticas que configuram o texto. Para o autor, a análise do texto deve extrapolar seus elementos linguísticos e o contexto não pode ser desconsiderado. $\mathrm{O}$ modelo de análise sugerido pelo autor leva em conta três conceitos básicos: gênero, comunidade discursiva e tarefas.

Segundo o autor, o gênero

compreende uma classe de eventos comunicativos, cujos membros compartilham um conjunto de propósitos comunicativos. Esses propósitos são reconhecidos pelos membros especialistas da comunidade de discurso dos pais e, portanto, constituem a razão para o gênero. Esse raciocínio molda a estrutura esquemática do discurso e influencia e restringe a escolha de conteúdo e estilo ${ }^{2}$ (SWALES, 1990, p. 58, tradução nossa)

Nessa abordagem, Swales prioriza o propósito comunicativo, mas, posteriormente, devido à dificuldade de identificar esse conceito, opta por entendê-lo não como predominante, mas como critério privilegiado na definição do gênero.

\footnotetext{
${ }^{2}$ A genre comprises a class of communicative events, the members of which share some set of communicative purposes. These purposes are recognized by the expert members of the parent discourse community and thereby constitute the rationale for the genre. This rationale shapes the schematic structure of the discourse and influences and constrains choice of content and style.
} 
Quanto à comunidade discursiva, Swales (1990, p. 24-27) apresenta seis características que a definem, a saber: conjunto de objetivos públicos em comum, formas de comunicação entre os participantes, função da troca de informações, capacidade de desenvolver seu próprio conjunto de gêneros, léxico específico e um nível de membros com um alto grau de conhecimento sobre o discurso.

A noção de comunidade discursiva, porém, recebeu críticas por não considerar o dissenso dentro de um grupo e seus avanços, além de se referir apenas a comunidades já formadas. Por isso, o conceito foi reformulado, propondo-se a ideia de comunidade discursiva de lugar, que seria um "grupo de pessoas que regularmente trabalham juntas e que têm uma noção estável, embora em evolução, dos objetivos propostos pelo seu grupo. Essa comunidade desenvolve uma gama de gêneros para orientar e monitorar os objetivos do grupo" (HEMAIS; BASI-RODRIGUES, 2005, p. 117).

Por fim, Swales entende que é por meio de atividades-tarefa que o gênero pode ser adquirido e apreendido.

$\mathrm{O}$ autor sugere um modelo de análise de resumos de artigos científicos, denominado Create a Research Space (CARS). Na primeira proposta desse modelo, obtida por meio da análise de introduções de artigo de pesquisa, o autor verificou a regularidade de quatro movimentos (moves): "movimento 1- estabelecer o campo da pesquisa; movimento 2- sumarizar pesquisas prévias; movimento 3- preparar a presente pesquisa; movimento 4- introduzir a presente pesquisa" (SWALES, 1984 apud HEMAIS; BASI-RODRIGUES, 2005, p. 120). Porém, essa primeira proposta teve de ser revisada, pois outros pesquisadores, ao utilizarem-na, enfrentavam dificuldades para diferenciar o movimento 1 do movimento 2 .

Dessa forma, em 1990, Swales propõe a segunda versão do modelo, agora mais sofisticada, já que considerou que cada movimento poderia ser desdobrado em alguns passos, classificados como obrigatórios ou opcionais.

Nessa proposta, o primeiro movimento diz respeito ao estabelecimento do território. Os passos desse movimento, que não são considerados obrigatórios, seriam: afirmar a importância da pesquisa, realizar generalizações quanto ao tópico, revisar a literatura. 
No segundo movimento, seria estabelecido o nicho da pesquisa e teria como passos a contra-argumentação, a indicação de lacunas no conhecimento (apenas este seria obrigatório), a provocação de questionamentos e a continuidade da tradição.

O terceiro movimento seria a ocupação do nicho, considerado o de maior relevância, pois aqui se instala o contexto em que determinado tipo de pesquisa faz sentido. Os passos desse movimento seriam: delineamento dos objetivos (obrigatório), apresentação da pesquisa (obrigatório) e de seus resultados, indicação da estrutura do artigo.

Diante do exposto, somos levados a crer que os pressupostos discutidos podem ser complementares e as justificativas para a adoção dessa perspectiva híbrida são apresentadas na próxima seção.

\section{Por uma abordagem híbrida para o ensino de gênero}

Conforme discutido nas seções anteriores, este trabalho tem por objetivo lidar com aspectos relacionados ao ensino e análise/produção de resumos acadêmicos na universidade.

A nosso ver, o Interacionismo Sociodiscursivo (ISD) e a Sociorretórica podem ser abordagens complementares, visto que ambas visam transformar objetos de estudo em objetos de ensino. Um dos primeiros pontos de contato entre essas teorias diz respeito à "visão do gênero como meio essencial para a comunicação humana". (CRISTÓVÃO, ARTEMEVA, 2018, p. 115).

Além desse aspecto, há ainda outras congruências entre as teorias: têm como foco a interação social e cultural, assumindo como fontes de inspiração as teorias sociais bakhtinianas e vygotskyanas; foram desenvolvidas para abordar questões de língua materna; focalizam as dimensões textuais e contextuais do gênero; valorizam a interação do estudante com o contexto social; analisam as convenções retóricas de gêneros, levando em conta os recursos linguísticos adequados. (CRISTÓVÃO, ARTEMEVA, 2018, p. 111-113).

Essas congruências, porém, não se realizam em todos os aspectos, podendo haver diferenças quanto à forma como as abordagens foram concebidas e desenvolvidas ou em como as teorias analisam os gêneros. No entanto, ressalta-se que as bases teóricas e os 
recursos dessas abordagens são suficientemente semelhantes para garantir uma conjunção produtiva. (CRISTÓVÃO, ARTEMEVA, 2018, p. 112-114)

Portanto, os usos híbridos de fundamentos teóricos e pedagógicos compatíveis possibilitam aos pesquisadores analisar além do que poderiam se estivessem utilizando apenas uma perspectiva. (CRISTÓVÃO, ARTEMEVA, 2018, p. 115).

\section{O gênero resumo acadêmico}

A escolha por trabalhar com o gênero resumo deveu-se por considerar que ele é uma das mais relevantes atividades na escola e na academia, sendo reiteradamente solicitado pelos professores nas diversas disciplinas. Além disso, “[...] as capacidades necessárias para a produção desse gênero são também indispensáveis para outros gêneros acadêmicos, tais como a resenha, os artigos, os relatórios etc" (MACHADO; LOUSADA; ABREU-TARDELLI, 2004, p. 14).

Neste trabalho, o resumo acadêmico é considerado como um tipo de resumo informativo/analítico que, conforme pesquisa realizada por Souza (2015, p. 104), reduz o textofonte a um terço ou um quarto de seu tamanho. Trata-se de uma exposição abreviada das ideias de outro texto (ou outra espécie de material), devendo manter o mesmo arranjo do texto-base, tendo por propósito mostrar aos leitores como o autor daquele texto organizou as informações. Nesse gênero, o autor não pode inserir sua opinião e nem informações que não constem no original (MACHADO; LOUSADA; ABREU-TARDELLI, 2005, p. 91). Além disso, normalmente, é produzido por outro enunciador, diferente do texto-fonte.

Para Schneuwly; Dolz (2004, p. 75), a tarefa 'resumo' deve ser encarada como um gênero que "leva ao extremo a atitude metalinguística em face de um texto, em que é preciso reconstruir a lógica enunciativa, sendo a situação escolar de comunicação, precisamente, aquela que solicita a demonstração da capacidade para essa atitude".

O resumo pertence à família de "gêneros resumitivos", tais como os Abstracts, resenhas, orelhas de livros. Porém, dentre esses gêneros, é possível diferenciar aqueles que são escritos pelo próprio autor (Abstracts) daqueles que são escritos por outrem e com propósitos comunicativos diferentes (resumos acadêmicos). 
A respeito do processo de produção, Antunes (2003, p. 45) afirma que a escrita, numa perspectiva de interação, supõe “[...] encontro, parceria, envolvimento entre os sujeitos, para que aconteça a comunhão das ideias, das informações e das intenções pretendidas". De acordo com a autora, a escrita não termina quando se textualizam as informações, mas algumas etapas inter-relacionadas devem ser levadas em conta, sendo que estas vão desde o planejamento e o desenvolvimento até a revisão e a reescrita (ANTUNES, 2003, p. 54).

De modo particular, a escrita acadêmica exige atenção a alguns fatores específicos, que podem estar relacionados à fase de preparação, execução, revisão e edição do texto. Segundo Motta-Roth; Hendges (2010, p. 14), com base em Swales; Feak (1994, 2000, 2004), os fatores seriam os seguintes: a definição do tópico que será desenvolvido no texto, atentando-se para a qualidade da literatura de referência; a imagem do público a que o texto se destina; as estratégias para expor pontos de vista, tecendo-se, por exemplo, relação do texto com outras obras já publicadas; organização da estrutura, para facilitar a leitura do texto; estilo formal; progressão lógica de ideias; revisão da versão final do texto.

As referidas autoras afirmam que os gêneros acadêmicos são construtos cujas especificidades estão relacionadas, pelo menos, a "tema e objetivo do texto [...]; público-alvo para quem escrevemos [...]; natureza e organização das informações que incluímos no texto" (MOTTA-ROTH; HENDGES, 2010, p. 23).

A prática de produzir resumos é necessária tanto do ponto de vista do aluno, o qual o utiliza como estratégia de estudo, quanto do professor, o qual o utiliza como estratégia de ensino e avaliação. (NASCIMENTO, 2005, p. 13). É relevante ressaltar ainda que os estudantes têm conhecimento de que o professor não é um leitor qualquer, "uma vez que as possíveis intervenções podem redimensionar o seu projeto discursivo. Tem-se aí um circuito comunicativo extremamente fechado, delimitado pelo quadro de participantes envolvidos (professor/aluno)" (SILVA; MATA, 2002, p. 129).

Levando em conta todos esses pressupostos, construímos a versão 1.0 do software "AutorIA", que tem por objetivo colaborar no processo de escrita de resumos acadêmicos por parte de graduandos em Letras, a princípio. Já neste ano, pretendemos iniciar algumas 
pesquisas para adaptar esse programa às necessidades de estudantes de cursos de outros campos disciplinares.

A seguir, delineamos a metodologia empregada na realização dos testes do referido software.

\section{Metodologia}

Nesta pesquisa, a metodologia, vinculada à Linguística Aplicada, teve uma perspectiva qualitativa de cunho interpretativista (MOREIRA; CALEFE, 2008).

Sendo assim, foram realizados testes para analisar o processo de interação entre os usuários e o computador, verificando, dessa forma, a facilidade de uso do sistema. (CONRAD; LEVI, 2002). Para tanto, lançamos mão de métodos empíricos, já que a usabilidade foi "acessada por testes de interface com usuários reais"3. (NIELSEN, 1994, p. 413).

Iniciamos as atividades no final do primeiro semestre de 2019, com uma avaliação heurística do software, considerada por Nielsen (1994) como o método mais informal e que envolve ter especialistas que julgam se cada elemento de diálogo segue princípios de usabilidade estabelecidos. Nessa tarefa, participaram as duas pesquisadoras envolvidas no projeto.

Posteriormente à avaliação heurística, no segundo semestre de 2019, três alunos ingressantes e três concluintes do curso de Letras da UFSJ foram convidados a utilizar o programa. Dessa forma, obtivemos dados sobre o desempenho de estudantes com menos e mais experiência em escrita/leitura. Salienta-se, ainda, que os estudantes foram avaliados individualmente.

Com relação às tarefas a serem realizadas, propusemos, a princípio, um questionário préteste constituído de questões objetivas, cuja finalidade foi coletar dados mais detalhados sobre os perfis dos estudantes envolvidos. A seguir, o teste de usabilidade teve início.

Durante esse teste, os estudantes produziram relatos em voz alta, os quais foram gravados e transcritos, constituindo os protocolos verbais. A técnica de produção de protocolos verbais, segundo Fujita (2009, p. 51), possibilita “analisar todo processo de verbalização do 
participante enquanto realiza sua atividade, com o mínimo de interação com o pesquisador". Concomitantemente à observação dos protocolos, foram registradas anotações consideradas pertinentes à análise.

Após a finalização desse teste, os participantes preencheram outro questionário, a fim de coletar opiniões sobre as ações, tarefas e características do sistema hipermídia. Esse questionário foi constituído de 25 questões de múltipla escolha, cujas respostas variaram segundo a escala de Likert (1932): "Concordo Totalmente", "Concordo", "Indeciso", "Discordo" e "Discordo Totalmente".

Os resultados de todo esse processo são apresentados a seguir.

\section{Discussão dos resultados}

Os dados da avaliação heurística demonstraram, de imediato, que a interface gráfica do programa não se mostrou totalmente atrativa e "legível", considerando que os comandos não estavam explícitos o suficiente para um acesso mais direto às informações.

Além disso, outras observações foram levantadas:

- a locução do tutorial não estava muito nítida e nos pareceu muito rápida;

- o processo da construção textual, que é o foco do programa, ainda precisava ser mais bem consolidado. Isso porque faltava ainda ao programa uma coesão entre suas fases, ou seja, faltava uma "engrenagem" entre os movimentos e passos retóricos;

- a necessidade de substituição de alguns comandos escritos em inglês por suas traduções (por exemplo, em vez de next, "próximo");

- a lista de tarefas que os estudantes precisavam cumprir também não ficou clara;

- a necessidade de o programa gerar outros tipos de referências bibliográficas além do artigo científico (online e impresso), considerando que há também outros gêneros de natureza semelhante àquele, como por exemplo, o capítulo de livro, as publicações em anais de congressos etc. 
Todas essas questões foram discutidas pela equipe e, juntos, tentamos configurar uma nova proposta de interface, com o intuito de que o software pudesse atender seus objetivos de forma mais eficaz.

Após esses ajustes, os estudantes foram convidados a testarem a usabilidade da versão atualizada do programa. Inicialmente, foi realizado um pré-teste, cujo objetivo foi sondar o perfil desses estudantes e sua relação com a tecnologia. Os resultados foram os seguintes:

- a maioria dos estudantes $(75 \%)$ tem grande familiaridade com o computador (mais de cinco anos de uso) e o utiliza mais de $10 \mathrm{~h}$ por semana;

- a totalidade dos estudantes utiliza a internet há três anos ou mais e navega mais de 10h por semana;

- a maioria desses estudantes (75\%) já utilizou ferramentas educacionais;

- metade dos participantes visita sites educacionais algumas vezes por semana; $25 \%$ utilizam-nos algumas vezes no mês e os outros 25\% navegam menos de uma vez por mês, sendo que a maioria $(75 \%)$ gasta menos de uma hora por semana nesses sites;

- as ferramentas mais utilizadas pelos estudantes são o Word (100\%), o Windows (75\%) e o Power Point (50\%).

Por meio desse levantamento, pôde-se perceber que a maioria dos estudantes tinha traquejo com o manuseio de recursos digitais. Sendo assim, supomos que o manejo da ferramenta trouxe agilidade aos processos e não foi uma variável que interferiu negativamente na produção escrita.

Após o pré-teste, os estudantes passaram a utilizar o software propriamente dito. Antes dessa utilização, contextualizamos a pesquisa aos envolvidos, indicamos os propósitos da produção do texto, as orientações sobre as ferramentas do programa e explicamos a eles a técnica do protocolo verbal. 
Dessa forma, esperávamos que os estudantes explicitassem muitas impressões em voz alta, mas isso não ocorreu, apesar de nossos estímulos. Diante disso, registramos não só os poucos comentários que eles externavam, mas também anotamos as modificações no programa que seriam necessárias, tendo em vista as ações que os estudantes realizavam durante o uso. Esses registros podem ser assim resumidos:

- inserir o limite máximo do resumo em páginas e não em palavras;

- aumentar ainda mais as letras dos links;

- inserir uma ferramenta que possibilite marcar trechos do texto que está sendo resumido;

- colocar lado a lado na tela o resumo e a proposta de autoavaliação deste;

- na ferramenta que possibilita analisar a frequência das palavras no texto original, criar um filtro para que a mesma palavra e seu plural não sejam contados duas vezes. Além disso, filtrar quinze e não dez palavras mais recorrentes;

- deixar mais visíveis as ferramentas de apoio à escrita (indicadores de relações lógico-semânticas, exemplo e análise de um resumo; sugestões de palavras que colaboram na organização do texto, exemplos de verbos que podem denotar as ações desenvolvidas pelo autor do texto original entre outras);

- inserir no programa atividades que trabalhem a capacidade de síntese dos estudantes;

- preencher os dados da referência bibliográfica do texto original no início do programa, para que ela seja gerada no cabeçalho do resumo a ser elaborado;

- indicar os caminhos de volta de forma mais direta;

- deixar as barras horizontais de arrastar mais nítidas;

- indicar com asterisco vermelho os passos obrigatórios do resumo;

- possibilitar a inserção de citação com recuo e parágrafo no resumo; 
- no movimento de conclusão do resumo, substituir o passo "conclusões do autor" por "considerações finais do autor", já que nem todo artigo científico termina com uma conclusão;

- repensar a forma de incluir os movimentos e passos no programa - muitos estudantes não entenderam o objetivo deles, porque não ouviram os tutoriais.

Conforme pudemos perceber, os comentários e observações dos alunos disseram respeito tanto a aspectos formais, como por exemplo, colocação de letras maiores nos comandos, até questões relacionadas à retórica, como a proposição de uma nova organização para lidar com os movimentos e passos.

Após a realização desse teste de usabilidade, os seis alunos participantes realizaram o pós-teste, para que coletássemos opiniões sobre o sistema hipermídia. A seguir, serão apresentados os resultados mais significativos.

No geral, as análises mostraram que os estudantes avaliaram de modo positivo o software. Os gráficos abaixo indicam as questões mais bem avaliadas, considerando que, na escala, o número 1 refere-se a "Discordo Totalmente" e o número 5, a "Concordo Totalmente":

\section{Gráfico 1- questão 17}

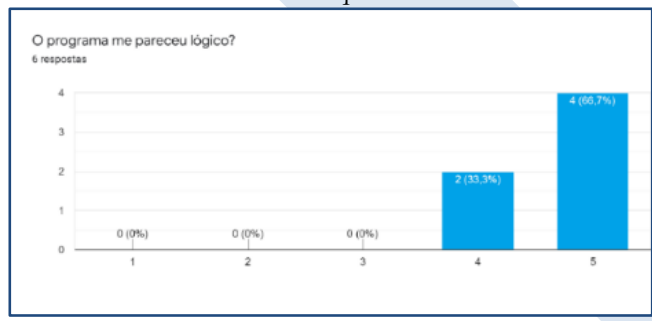

Gráfico 2 - questão 13

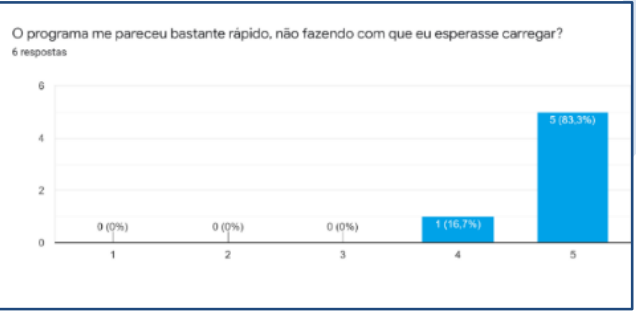


Gráfico 3 - questão 20

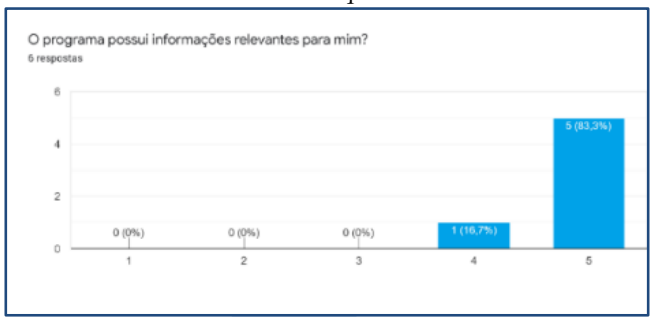

Gráfico 4 - questão 7

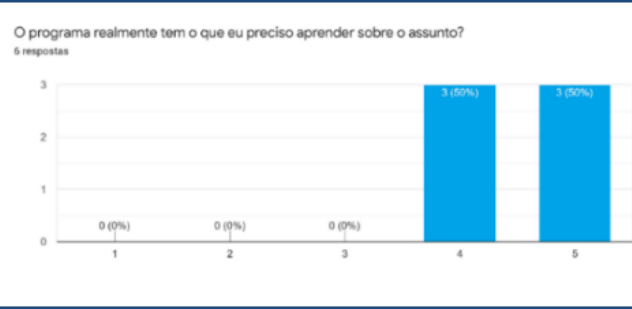

Gráfico 5 - questão 9

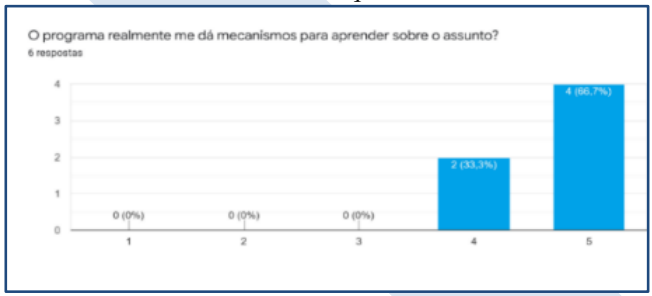

Gráfico 6 - questão 25

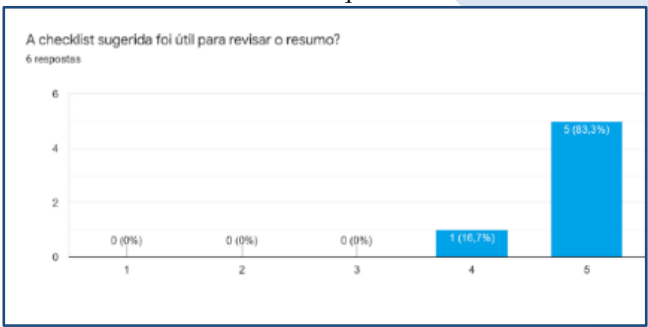

Como pudemos perceber, os quesitos que mais receberam avaliações favoráveis ("concordo" e "concordo totalmente") relacionaram-se ao fato de o programa ser lógico, 
rápido, apresentar informações relevantes e de que os alunos precisam, à oferta de mecanismos para aprender sobre o tema (resumo acadêmico) e à utilidade do roteiro de autoavaliação sugerido. Esses resultados muito nos animaram, pois constatamos que importantes aspectos do software e do processo de escrita de resumos acadêmicos foram contemplados satisfatoriamente.

Por outro lado, alguns critérios receberam apreciações negativas e/ou apresentaram um número proporcionalmente elevado de indecisos:

\section{Gráfico 7 - questão 3}

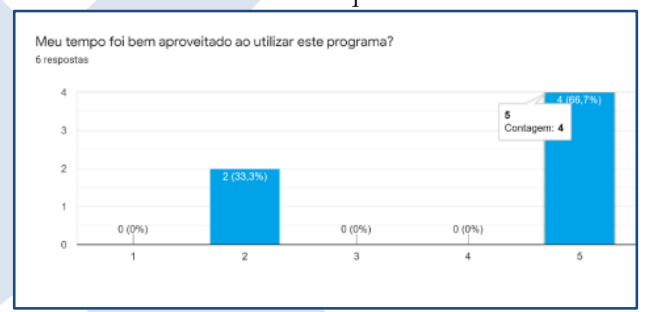

Gráfico 8 - questão 2

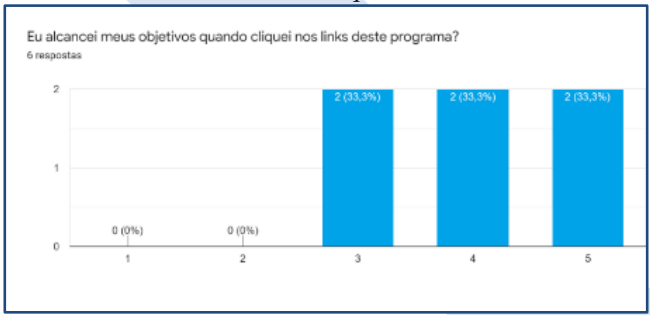

Gráfico 9 - questão 5

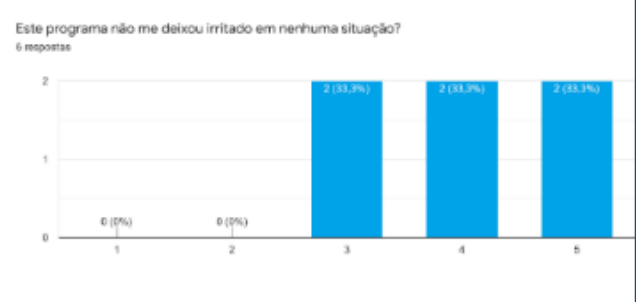



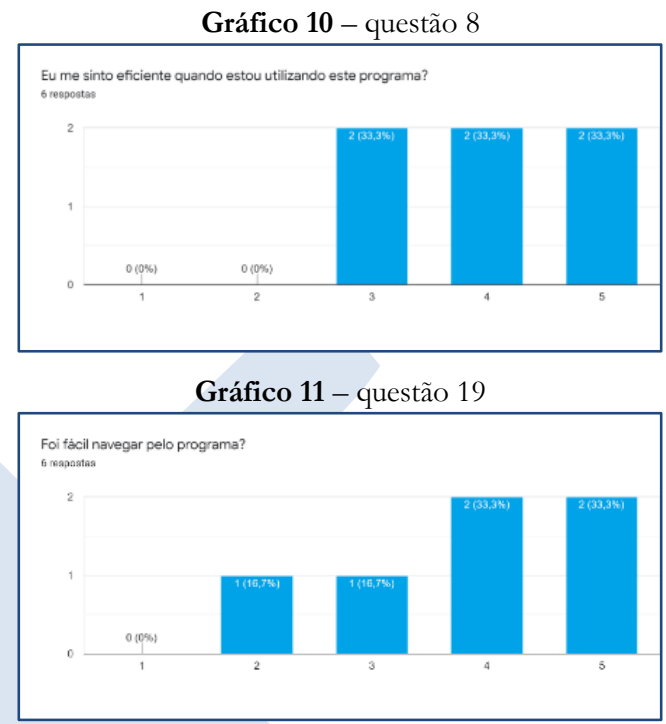

Gráfico 12 - questão 24

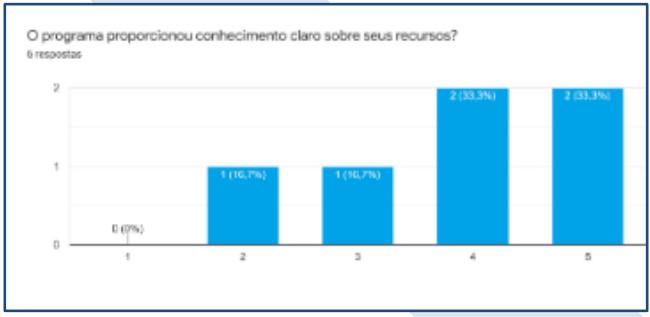

Os gráficos apontam que, apesar das avaliações majoritariamente positivas, alguns aspectos, que estão muito relacionados, devem ser repensados no momento de elaborarmos a segunda versão do software (versão 2.0): houve estudantes insatisfeitos com relação ao melhor aproveitamento do tempo de uso, o que pode ser alcançado por meio da apresentação mais clara dos recursos de que o software dispõe, promovendo o aumento da "legibilidade" dos linkes e a melhoria da navegabilidade. Essas alterações também poderão fazer com que os estudantes alcancem seus objetivos mais rapidamente, ficando menos irritados durante a navegação, fatos que poderão despertar nesses alunos a sensação de eficiência durante o uso do programa. 
Por fim, apontamos os quesitos que, na nossa concepção, foram os menos satisfatórios, já que o número de indecisos foi maior ou igual ao número de avaliações positivas:

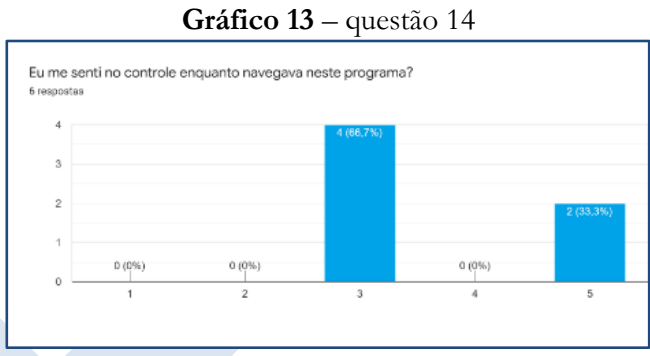

Gráfico 14 - questão 18

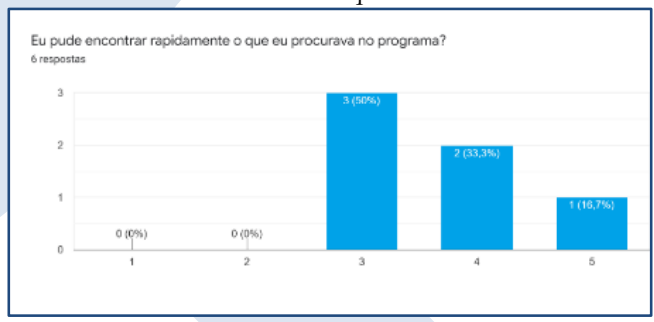

Acreditamos que esses últimos resultados sejam uma consequência daqueles que constam nos gráficos de 7 a 12, o que nos leva à suposição de que, ao repensarmos os precedentes, estaremos impactando positivamente os ulteriores.

\section{Considerações finais}

O desenvolvimento desta pesquisa ofereceu um pequeno indício da complexidade que envolve um gênero textual e seu processo de didatização, o qual foi intermediado por recursos tecnológicos. Apesar disso, somos levados a crer que vale a pena investir nessa confluência, pois os resultados foram animadores.

Subsequentemente, procederemos às discussões sobre os ajustes a serem implementados na versão 2.0 do programa, com especial observância dos itens cuja apreciação não foi satisfatória. 
Destarte, continuaremos envidando esforços para que o "AutorIA", num futuro muito próximo, possa fazer parte da rotina de graduandos e professores de Letras, contribuindo, de forma significativa, para a produção de resumos acadêmicos. Paralelamente, estamos realizando pesquisas sobre esse tema em outros cursos, a fim de que o software atenda às peculiaridades de diferentes campos disciplinares.

\title{
THE PRODUCTION OF ACADEMIC ABSTRACTS: \\ A PRELIMINARY STUDY ON THE USABILITY OF THE “AUTORIA - MEU RESUMO” SOFTWARE
}

\begin{abstract}
This paper is part of my postdoctoral program, carried out from March 2019 to February 2020. It aimed to observe some aspects related to teaching-learning issues applied to academic summaries. In this paper, the discussion about the test results of the usability of the "AutorIA" software, which is an outcome of this piece of research, is emphasized. These tests intended to analyze the process related to the interaction between students and computer, checking, in this way, the ease of use of the system (CONRAD; LEVI, 2002). The theoretical support for the software development was based on a hybrid perspective: on the one hand, it was based on the principles of Sociodiscursive Interactionism proposed by Bronckart $(1999,2006)$ and Cristóvão (2013), as well as its didactic perspective, according to Schneuwly and Dolz (2004); on the other hand, it was gleaned from aspects of the Socio-rhetorical Theory proposed by Swales (1990) and Askehave; Swales (2001), prioritizing the "Create a Research Space Model" (CARS model) and its possible adaptations to the academic summary. The methodology, bounded to the Applied Linguistics, was based on a qualitative perspective of interpretative nature (MOREIRA; CALEFE, 2008), with an empirical methods approach. The results showed that students, in general, gave a positive feedback about the software used for producing academic summaries, demonstrating that technology proves to be an important resource in the didactization process.
\end{abstract}

KEYWORDS: Academic Summary; Software; Usability Tests.

\section{REFERÊNCIAS}

ANTUNES, Irandé. Aula de português: encontro e interação. São Paulo: Parábola, 2003.

ASKEHAVE, I.; SWALES, J. M. Genre identification and communicative purpose: a problem and a possible solution. Applied Linguistics, v. 22, n. 2, p. 195-212, 2001.

BAKHTIN, Mikhail Mikhailovitch. Estética da criação verbal. São Paulo: Martins Fontes, 1992.

BRONCKART, Jean-Paul. Atividade de linguagem, discurso e desenvolvimento humano. Trad. Anna Rachel Machado e Maria de Lourdes Meirelles Matêncio. Campinas: Mercado de Letras, 2006. 
- Restrições e liberdades textuais, inserção social e cidadania. Revista da $A N$ POLL. São Paulo: v. 19, p. 231-256, 2005.

. Atividade de linguagem, textos e discursos: por um interacionismo sociodiscursivo. Trad. Anna Rachel Machado e Péricles Cunha. São Paulo: Educ, 1999.

CONRAD, M. D.; LEVI, F. G. Usability Testing of World Wide Web Sites, 2002. Disponível em: <http://stats.bls.gov/ore/htm_papers/st960150.htm>. Acesso em: 18 jul. 2019.

CRISTÓVÃO, Vera Lúcia Lopes. Para uma expansão do conceito de capacidades de linguagem. In: BUENO, Luzia; LOPES, Maria Ângela Paulino Teixeira; CRISTÓVÃO, Vera Lúcia Lopes. Gêneros textuais e formacão inicial: uma homenagem à Malu Matêncio. Campinas: Mercado de Letras, 2013.

; ARTEMEVA, N. Towards a hybrid approach to genre teaching: comparing the Swiss and Brazilian schools of socio-discursive interactionism and rhetorical genre studies. Diálogo das Letras. Pau dos Ferros: v. 7, n. 2, p. 101 - 120, maio/ago. 2018.

; STUTZ, L. Sequencias didáticas: semelhanças e especificadas no contexto francófono com L1 e no contexto brasileiro como LE. In: SZUNDY, P. T. C. et al (Orgs). Linguística Aplicada e sociedade: ensino e aprendizagem de línguas no contexto brasileiro. Campinas: Pontes Editores, 2011, p. 17-40.

DE PIETRO, J.-F.; ERARD, S.; KANEMAN-POUGATCH, M. Un modèle didactique du "débat": de l'objet social à la pratique scolaire. Enjeux, v. 39/40, p. 100-129, 1996/1997.

DOLZ, J.; PASQUIER, A.; BRONCKART, J.P. A aquisição do discurso: emergência de uma competência ou aprendizagem de diferentes capacidades de linguagem? Nonada: Letras em Revista, n. 28, vol. 1, maio de 2017.

FUJITA, Mariângela Spotti Lopes. A técnica introspectiva e interativa do protocolo verbal para observação do contexto sociocognitivo da indexação na catalogação de livros em bibliotecas universitárias: aplicação e análise. UNESP, 2009. Disponível em: < $\underline{\text { http://books.sci- }}$ elo.org/id/wcvbc/pdf/boccato-9788579830150-05.pdf>. Acesso em: 16 jul. 2019.

HEMAIS, BARBARA; BASI-RODRIGUES, Bernardete. A proposta sociorretórica de John M. Swales para o estudo de gêneros textuais. In: MEURER, J. L.; BONINI, Adair; MOTTA-ROTH, Désirée (Orgs.). Gêneros: teorias, métodos, debates. São Paulo: Parábola, 2005. p. 108-129.

LENHARO, R. I. Participação social por meio da música e da aprendizagem de língua inglesa em um contexto de vulnerabilidade social. 2016. Dissertação (Mestrado em Programa de Pós-Graduação em Estudos da Linguagem) - Universidade Estadual de Londrina, 2016.

LIKERT, R. A Technique for the Measurement of Attitudes. New York: Archives of Psychology, 1932. 
MACHADO, Anna Rachel; CRISTÓVÃO, Vera Lúcia Lopes. A construção de modelos didáticos de gênero: aportes e questionamentos para o ensino de gêneros. Linguagem em (Dis)curso - LemD. Tubarão: v. 6, n. 3, p. 547-573, set./dez. 2006.

; LOUSADA, Eliane; ABREU-TARDELLI, Lília Santos. O resumo escolar: uma proposta de ensino do gênero. SIGNUM: Estudos Linguísticos. Londrina: n. 8/1, p. 89-101, jun. 2005.

. A perspectiva interacionista sociodiscursiva de Bronckart. In: MEURER, J.L.; BONINI, Adair; MOTTA-ROTH, Désirée (Orgs). Gêneros: teorias, métodos, debates. São Paulo: Parábola, 2005, p. 237-259.

(Coord.); LOUSADA, Eliane; ABREU-TARDELLI, Lília Santos. Resumo. São Paulo: Parábola, 2004.

MATÊNCIO. Maria de Lourdes Meirelles. Textualização, ação e atividade: reflexões sobre a abordagem do interacionismo sociodiscursivo. In: GUIMARÃES, Ana Maria de Mattos; MACHADO, Anna Rachel; COUTINHO, Antônia (Orgs.). O interacionsimo sociodiscursivo: questões epistemológicas e metodológicas. Campinas: Mercado de Letras, 2007.

MIQUELANTE, Marileuza Ascêncio. Saberes necessários à formação docente - articulação desafiadora a partir de sequências de formação, de ensino e didática como instrumentos mediadores. 2019. 846f. Tese de Doutorado. Programa de Pós-graduação em Estudos da Linguagem, Universidade Estadual de Londrina, Paraná, 2019.

MOREIRA; CALEFE. Metodologia da pesquisa para o professor pesquisador. Rio de Janeiro: Lamparina, 2008.

MOTTA-ROTH, Désirée; HENDGES, Graciela Rabuske. Produção textual na universidade. São Paulo: Parábola, 2010.

NASCIMENTO, Mizael Inácio do. A produção do gênero resumo. 2005. 144p. Dissertação de Mestrado. Programa de Pós-Graduação em Letras. Universidade Federal de Pernambuco, Recife, 2005.

NIELSEN, Jakob. Usability inspection methods. 1994. Boston. Disponível em: <http://www.idemployee.id.tue.nl/g.w.m.rauterberg/lecturenotes/0h420/nielsen[1994].pdf>. Acesso em 20 jul. 2019.

SCHNEUWLY, Bernard; DOLZ, Joaquim. Gêneros orais e escritos na escola. Campinas: Mercado de Letras, 2004.

SILVA, Jane Quintiliano Guimarães; MATA, Maria Aparecida da. Proposta tipológica de resumos: um estudo exploratório das práticas de ensino da leitura e da produção de textos acadêmicos. Scripta, Belo Horizonte, v. 6, n. 11, p. 123-133, 2\%/2002.

SOUZA, Rita Rodrigues de. Resumo escolar no ensino médio técnico integrado integral: uma experiência de leitura e escrita em uma abordagem sociorretórica. 2015. 219f. Tese de 
Doutorado. Programa de Pós-Graduação em Estudos Linguísticos, do Instituto de Biociências, Letras e Ciências Exatas, Universidade Estadual Paulista "Júlio de Mesquita Filho", campus São José do Rio Preto, São Paulo, 2015.

STRIQUER, Marilúcia, dos Santos Domingos. O método de análise de textos desenvolvido pelo Interacionismo Sociodiscursivo. Eutomia, Recife, 14 (1): p. 313-334, dez. 2014.

SWALES, John. M.; FEAK, Christine. B. Academic writing for graduate students. Ann Arbor: The University of Michigan Press, 2004.

igan Press, 2000.

. B. English in today's research world. Ann Arbor: The University of Mich-

Michigan Press, 1994.

B. Academic writing for graduate students. Ann Arbor: The University of

SWALES, John M. Genre Analysis: English in academic and research settings. Cambridge: CUP, 1990.

Research Into the Structure of Introductions to Journal Articles and its Application to the Teaching of Academic Writing. In: WILLIAMS, R.; SWALES, J; KIRKMAN, J. Common Ground: shared interests in ESP and communication studies. ELT Documents 117, 1984.

Recebido em: 19/05/2020.

Aprovado em: 10/06/2020. 